\title{
Genome-wide and Ordered-Subset linkage analyses provide support for autism loci on I7q and I9p with evidence of phenotypic and interlocus genetic correlates Jacob L McCauley ${ }^{1}$, Chun Li1,2, Lan Jiang1, Lana M Olson ${ }^{1}$, Genea Crockett ${ }^{1}$, Kimberly Gainer ${ }^{1}$, Susan E Folstein ${ }^{3}$, Jonathan L Haines ${ }^{1}$ and James S Sutcliffe*1
}

Address: ${ }^{1}$ Center for Human Genetics Research, Departments of Molecular Physiology \& Biophysics, Vanderbilt University, Nashville, TN, USA, ${ }^{2}$ Biostatistics, Vanderbilt University, Nashville, TN, USA and ${ }^{3}$ Department of Psychiatry and Behavioral Sciences, Johns Hopkins University, Baltimore, MD, USA

Email: Jacob L McCauley - jacob.mccauley@vanderbilt.edu; Chun Li - chun@chgr.mc.vanderbilt.edu; Lan Jiang - jiang@chgr.mc.vanderbilt.edu; Lana M Olson - olson@chgr.mc.vanderbilt.edu; Genea Crockett - crockett@chgr.mc.vanderbilt.edu;

Kimberly Gainer - gainer@chgr.mc.vanderbilt.edu; Susan E Folstein - sfolstein@rcn.com;

Jonathan L Haines - jonathan@chgr.mc.vanderbilt.edu; James S Sutcliffe* - james.s.sutcliffe@vanderbilt.edu

* Corresponding author

Published: 12 January 2005

BMC Medical Genetics 2005, 6:I doi:I0.1 186/147|-2350-6-1
Received: 18 October 2004

Accepted: 12 January 2005

This article is available from: http://www.biomedcentral.com/l47/-2350/6/I

(c) 2005 McCauley et al; licensee BioMed Central Ltd.

This is an Open Access article distributed under the terms of the Creative Commons Attribution License (http://creativecommons.org/licenses/by/2.0), which permits unrestricted use, distribution, and reproduction in any medium, provided the original work is properly cited.

\begin{abstract}
Background: Autism is a neurobehavioral spectrum of phenotypes characterized by deficits in the development of language and social relationships and patterns of repetitive, rigid and compulsive behaviors. Twin and family studies point to a significant genetic etiology, and several groups have performed genomic linkage screens to identify susceptibility loci.

Methods: We performed a genome-wide linkage screen in 158 combined Tufts, Vanderbilt and AGRE (Autism Genetics Research Exchange) multiplex autism families using parametric and nonparametric methods with a categorical autism diagnosis to identify loci of main effect. Hypothesizing interdependence of genetic risk factors prompted us to perform exploratory studies applying the Ordered-Subset Analysis (OSA) approach using LOD scores as the trait covariate for ranking families. We employed OSA to test for interlocus correlations between loci with LOD scores $\geq 1.5$, and empirically determined significance of linkage in optimal OSA subsets using permutation testing. Exploring phenotypic correlates as the basis for linkage increases involved comparison of mean scores for quantitative trait-based subsets of autism between optimal subsets and the remaining families.
\end{abstract}

Results: A genome-wide screen for autism loci identified the best evidence for linkage to $|7 q| 1.2$ and $|9 p| 3$, with maximum multipoint heterogeneity LOD scores of 2.9 and 2.6, respectively. Suggestive linkage (LOD scores $\geq 1.5$ ) at other loci included $3 p, 6 q, 7 q, 12 p$, and 16p. OSA revealed positive correlations of linkage between the 19p locus and 17q, between 19p and 6q, and between $7 q$ and $5 p$. While potential phenotypic correlates for these findings were not identified for the chromosome 7/5 combination, differences indicating more rapid achievement of "developmental milestones" was apparent in the chromosome 19 OSA-defined subsets for $17 q$ and $6 q$. OSA was used to test the hypothesis that $19 p$ linkage involved more rapid achievement of these milestones and it revealed significantly increased LOD* scores at $19 \mathrm{p} \mid 3$.

Conclusions: Our results further support $19 \mathrm{p} / 3$ as harboring an autism susceptibility locus, confirm other linkage findings at $|7 q| \mid .2$, and demonstrate the need to analyze more discreet trait-based subsets of complex phenotypes to improve ability to detect genetic effects. 


\section{Background}

Autism (OMIM \# 209850) is a neurobehavioral disorder involving deficits in language and social abilities and patterns of repetitive behaviors, restricted interests and resistance to change. The most recent estimate of population prevalence for the broader autism spectrum indicates a rate of $34 / 10,000(\sim 1 / 300)$ [1], with a male: female ratio of $4: 1$ [2,3]. Evidence from various studies indicates idiopathic autism has a complex genetic etiology. Twin studies show a concordance of $60 \%$ among monozygotic (MZ) twins and $0 \%$ among dizygotic (DZ) pairs for classic autism, but this increases to $92 \%$ for $\mathrm{MZ}$ pairs and $10 \%$ for $\mathrm{DZ}$ pairs when a broader phenotype of related social and language abnormalities is included $[4,5]$. The sibling recurrence risk is suggested to be $\sim 3-10 \%$ but may be underestimated as a result of "stoppage rules" [6-8], and the relative risk is thus $30-100$ times that in the general population $[5,7]$. Heritability is estimated at $90 \%$, which is among the highest for psychiatric disorders. While the data do not strongly endorse any one model for inheritance, twin and family studies support a multilocus etiology with as many as 10-20 loci (reviewed in [9-11]).

Genome-wide screens of multiplex autism families for susceptibility loci [12-22] have identified a few genomic regions in common across multiple studies; $7 \mathrm{q}$ and $2 \mathrm{q}$ have received the greatest attention $[17,19,20,23-28]$, with support from chromosomal abnormalities affecting these regions in idiopathic autism (reviewed in [29]). Genetic studies of autism are substantially complicated by clinical and locus heterogeneity, and it is possible that epistatic or epigenetic mechanisms may play important roles in genetic etiology [9,30]. Analytical strategies that address the latter concerns are limited, and most studies to date have focused on analysis of main effects using a global autism diagnosis to define affection status. Moving forward, more sophisticated approaches are being proposed in which trait-based subsets of the broader autism phenotype are used in genetic analyses. Similarly, given the interdependence of genes and their protein products within biological systems, analytical approaches that address potential interaction between susceptibility loci will also be critical to characterizing gene-phenotype relationships in autism.

We report a second generation 10-cM microsatellite-based genomic screen of multiplex autism families. The dataset for this screen includes 71 families recruited by the Tufts/ New England Medical Center, a well-characterized set of 85 families from the Autism Genetics Resource Exchange (AGRE), and 2 families from Vanderbilt University. Several sites of suggestive linkage are identified, although none meet criteria for genome-wide significance. The loci with greatest support for linkage were $17 \mathrm{q} 11.2$ and 19p13; the latter site demonstrated significantly increased allele-sharing when the Ordered-Subset Analysis (OSA) algorithm was employed using a quantitative trait-based autism phenotypic subset related to specific "developmental milestones" as a covariate to rank families.

\section{Methods \\ Sample and Demographics}

The demographics for the 158 family dataset comprising the studies in this report are shown in Table 1. Families were recruited through three sites: (a) 71 families from the Tufts/NEMC site, (b) 2 families from the Vanderbilt University site, and (c) the remainder of families (85) were chosen from the AGRE repository based on our own recruitment criteria. Multiplex families (mostly affected sibling-pairs) had one affected individual who met full criteria for autistic disorder based on Autism Diagnostic Interview-Revised (ADI-R; [31-33])) algorithm scores, while the second individual either met criteria or in some cases was under the cut-off by only one or two points. Exclusion criteria included dysmorphic features, abnormal karyotype, diagnosis of fragile X syndrome, and other genetic disorders of known etiology. Individuals were assessed by the respective groups using the ADI-R at a developmental age $>18$ months; Tufts/NEMC and Vanderbilt groups included individuals between the ages of 4 and 22; in cases in which ADI-R interviews were performed initially at $<4$ years, they were repeated when the probands reached 4 years of age. All individuals were additionally assessed using the Autism Diagnostic Observation Schedule $[32,34]$ and the Vineland Adaptive Behavior Scales - Interview Edition [35,36].

\section{Genotype data and statistical analysis}

DNA from Tufts and Vanderbilt samples was obtained from peripheral blood or immortalized lymphoblastoid cell lines using the PureGene Kit (Gentra Systems). While a minority of families from the Tufts/NEMC cohort had been genotyped previously [13], both new and previously genotyped families were genotyped by deCODE (Reykjavik, Iceland) using their 500 marker ( $~ 8 \mathrm{cM}$ intermarker spacing) panel and corresponding genetic map [37]. Genotype data were obtained from the AGRE website [38] for families whose samples were purchased from the AGRE repository and included in this study. Clinical procedures and genotyping for the AGRE sample has been described previously $[18,39]$. AGRE samples and corresponding genotype data had a distinct but overlapping panel of markers compared to the Tufts and Vanderbilt families. AGRE genetic markers were placed on the deCODE map, with order and spacing properly insured through exhaustive comparisons between genotyped markers, available genetic maps, and physical DNA sequence assemblies in both public and Celera databases. 
Table I: Sample Demographics

\begin{tabular}{lr}
\hline Families in Linkage Screen & $\mathbf{I 5 8}$ \\
\hline Tufts/NEMC & 71 \\
AGRE & 85 \\
Vanderbilt & 2 \\
\hline Affected Individuals & 333 \\
Males & 257 \\
Females & 76 \\
\hline Tufts/NEMC Total & 148 \\
Males & 117 \\
Females & 31 \\
AGRE Total & 181 \\
Males & 137 \\
Females & 44 \\
Vanderbilt Total & 4 \\
Males & 3 \\
Females & 1 \\
\hline Age at ADI (range) & $2-46.7$ \\
\hline Tufts/NEMC* & $2-46.7$ \\
AGRE & $2-38.0$ \\
Vanderbilt & $6.2-9.2$
\end{tabular}

\section{Ethnicity (Individuals)}

\begin{tabular}{lr}
\hline Caucasian (242) & \\
Tufts/NEMC (I30) & $\mathbf{7 3 . 0 \%}$ \\
AGRE (108) & $87.8 \%$ \\
Vanderbilt (4) & $59.7 \%$ \\
\hline Hispanic-Latino (14) & $100.0 \%$ \\
AGRE (14) & $4.2 \%$ \\
\hline African-American (8) & $7.7 \%$ \\
Tufts/NEMC (6) & $2.4 \%$ \\
AGRE (2) & $4.1 \%$ \\
\hline Asian (8) & $1.1 \%$ \\
Tufts/NEMC (2) & $2.4 \%$ \\
AGRE (6) & $1.4 \%$ \\
\hline Multi-ethnic (14) & $3.3 \%$ \\
AGRE (I4) & $4.2 \%$ \\
\hline Other (2) & $7.7 \%$ \\
Tufts/NEMC (2) & $\mathbf{0 . 6 \%}$ \\
\hline Unknown (45) & $1.4 \%$ \\
Tufts/NEMC (8) & $13.5 \%$ \\
AGRE (37) & $5.4 \%$ \\
\hline
\end{tabular}

I.Q. estimate distributions

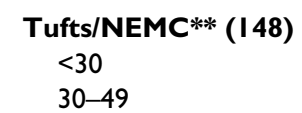

Table I: Sample Demographics (Continued)

\begin{tabular}{lr}
\hline $50-69$ & 37 \\
$70+$ & 17 \\
Unknown & 60 \\
\hline AGRE*** (18I) & 17 \\
$<30$ & 27 \\
$30-49$ & 15 \\
$50-69$ & 13 \\
$70+$ & 109 \\
Unknown & \\
\hline Vanderbilt*** (4) & 1 \\
$<30$ & 1 \\
$30-49$ & 0 \\
$50-69$ & 2 \\
$70+$ & 0 \\
Unknown & \\
\hline
\end{tabular}

*ADI-Rs performed $<4$ yrs were repeated at 4 yrs for Tufts/NEMC families

**iQ estimates are based on the Vineland Daily Living standard scores ***. $\mathrm{Q}$ estimates are based on overall Vineland Adaptive Behavior standard scores

Genotype data for each chromosome underwent thorough error detection and genotype confirmation. Initially, data were tested for Mendelian inconsistencies using PEDCHECK [40] and RELPAIR [41], followed by SIMWALK2 [42] for haplotype construction to detect genotyping errors reflected by unlikely double recombinants. In the event of a highly improbable genotype, the data for that marker were excluded for the family.

Allele frequencies were estimated using genotype data from all unrelated individuals in the combined dataset, consisting of more than 300 chromosomes. Allele frequencies were compared with available data from other Caucasian populations, and no significant differences were observed (data not shown). The LAPIS program of the PEDIGENE system [43] was used to output appropriate analysis files for the different programs.

Linkage was analyzed using both model-dependent and model-independent methods. For autosomes, two-point and multipoint heterogeneity LOD (HLOD) scores were calculated under both dominant and recessive models using Allegro [44]. Disease allele frequency was estimated to be 0.01 and 0.1 for dominant and recessive models, respectively. Phenotypic status was only considered for affected individuals, and other family members were designated as having an unknown phenotypic status. Nonparametric allele-sharing LOD* $^{*}$ values were calculated using affected relative pair data based on an exponential model using the $S_{\text {pairs }}$ scoring function as recommended 
Table 2: Linkage Data for Loci with LOD Scores > I.5

\begin{tabular}{|c|c|c|c|c|}
\hline Chromosome & deCODE cM & Marker & HLOD & LOD* \\
\hline $3 p 25.3$ & 25 & D3S369I & $1.76^{R}$ & 2.22 \\
\hline $6 q 23.2$ & $|3|$ & D6SI656 & $1.6 \mathrm{IR}^{\mathrm{R}}$ & 0.62 \\
\hline $7 q 35$ & 152 & D7S2195 & $1.65^{R}$ & 1.14 \\
\hline $12 p \mid 2.1$ & 45 & DI2SI59I & $1.50^{R}$ & 1.43 \\
\hline $16 p \mid 3.2$ & 15 & ATA4IE04 & $1.64^{\mathrm{D}}$ & 1.38 \\
\hline $16 p 13.12$ & 33 & DI6S3062 & $1.87^{D}$ & 1.60 \\
\hline $16 p 12.3$ & 43 & DI6S490 & $1.80^{\mathrm{D}}$ & 1.49 \\
\hline$|7 q| 1.2$ & 53 & DI7SI294 & $2.85^{\mathrm{D}}$ & 2.13 \\
\hline $17 q 21.2$ & 69 & DI7SI 299 & $1.90^{\mathrm{D}}$ & 1.60 \\
\hline $19 p 13.11$ & 40 & DI9S930 & $2.55^{R}$ & 1.92 \\
\hline $19 p 13.11$ & 56 & DI9SII3 & $2.20^{R}$ & 1.39 \\
\hline
\end{tabular}

R: recessive; D: dominant

by McPeek [45]. NPL scores and corresponding P-values were also calculated by Allegro. Data from the X chromosome were analyzed using ASPEX [46] and FASTLINK [47] to calculate two-point and multipoint MLOD scores. Peak parametric (HLOD) or nonparametric LOD* scores $\geq 1.5$ were considered as "suggestive" evidence for linkage and listed in Table 2, along with corresponding peak marker, deCODE cM location, and chromosomal band position.

The nonparametric genome-wide significance threshold $[48,49]$ for linkage at the $\mathrm{P}=0.05$ level was determined by conducting simulations using Merlin [50] with the current dataset. The Simulate option in Merlin was used to produce 1000 random datasets that preserve the properties of the original data for marker informativeness, spacing and missing data patterns. An empirical significance threshold was determined by using the $95^{\text {th }}$ percentile of the resulting distribution.

OSA [51] identifies genetically more homogeneous subsets of the overall data by ordering families according to covariate trait values in ascending or descending order. OSA takes the first family and calculates an allele-sharing LOD* score. In an iterative process, OSA successively adds families, re-calculating LOD* scores with each addition, and it identifies the division in the dataset at which maximum linkage is obtained on the chromosome being analyzed. Permutation testing is used to determine the empirical significance of the observed results. OSA has been applied with success to identify or increase evidence in support of linkage to complex disease susceptibility loci [52-54].

To explore potential genetic interaction or other genetic correlations between sites of main effect (i.e. suggestive linkage), OSA was applied using family-specific LOD scores as the covariate trait. Families were ranked according to the family-specific LOD score at peak sites demonstrating LOD scores $\geq 1.5$. Allele-sharing analysis was performed for the other six chromosomes using the OSA algorithm. For instances of empirically significant increases in evidence for linkage, we explored the nature of the genetic correlation to ask whether it reflected clinical correlations in the respective subsets. We employed ADI-based factor subsets, identified by principal components analyses of ADI/ADI-R items, to represent putative phenotypic subsets in autism $[55,56]$. The ADI-based variable clusters correspond to "(1) language, (2) social intent, (3) developmental milestones, (4) rigid-compulsive behaviors, (5) savant skills, and (6) sensory aversion", as determined by Folstein and colleagues [55]; and (7) "insistence on sameness" as described by Cuccaro and colleagues [56]. We thus compared the seven ADI-based factor score means (both the mean of family means and the mean of affected individuals) using a t-test for the families above and below the OSA-determined split in the dataset resulting in maximal linkage. Subsequent analysis involved specific examination of the "developmental milestones" cluster. The milestones factor indexes on the following ADI items: "(1) To walk unaided; (2) to sit unaided on flat surface; (3) age of first single words; (4) age of first phrase; (5-6) acquisition of bladder control: daytime, night; (7) acquisition of bowel control."

Analysis of the "developmental milestones" factor as a potential phenotypic subset related to the autism linkage correlations was performed by applying the OSA algorithm. We used "developmental milestones" family means, normalized via SAS and Box-Cox transformation procedures, as an ascending ranking covariate. LOD* scores were calculated according to the OSA algorithm, and the resulting increase in linkage achieved with the 
OSA-determined family subset was analyzed through permutation testing.

Approval for these studies was granted by the respective Institutional Review Boards at Tufts University School of Medicine/New England Medical Center and Vanderbilt University Medical Center. Additionally, all studies were performed with informed consent provided by the families participating in the research.

\section{Results}

Seven chromosomes revealed one or more regions of linkage with a model-dependent or model-independent LOD score $\geq 1.5$ (Figure 1). No locus reached the empirically derived genome-wide significance level of 2.92. These suggestive loci include 3p25, 6q23, 12p12, 16p12-p13, 17q11, 17q21 and 19p13 (Table 2). Data provide the most compelling support for $17 \mathrm{q} 11.2$ and $19 \mathrm{p} 13$ as harboring autism susceptibility loci.

For $17 \mathrm{q} 11.2$, peak linkage was observed at $53 \mathrm{cM}$, corresponding to marker D17S1294 (Table 2), at which we see a multipoint HLOD of 2.85. Nonparametric multipoint analysis revealed an allele-sharing $\mathrm{LOD}^{*}$ score of 2.13 and an NPL score of $2.84(\mathrm{P}=0.0024)$. A second telomeric peak can be distinguished on 17 at $\sim 69 \mathrm{cM}$, corresponding to $17 \mathrm{q} 21.2$. Marker D17S1299 at this site yielded a HLOD of 1.9 , a LOD* of 1.66 and an NPL score of $2.26(\mathrm{P}=$ $0.012)$. The more proximal peak at $\sim 53 \mathrm{cM}$ lies in close proximity $(\sim 150 \mathrm{~kb})$ to the serotonin transporter (SLC6A4) locus, long considered to be an attractive functional candidate gene for autism and other neuropsychiatric conditions. Figure 2 shows multipoint LOD score plots for both dominant and recessive parametric (HLOD) and nonparametric allele-sharing $\mathrm{LOD}^{*}$ values for chromosomes 17 and 19.

The second most significant result was observed on 19p13, where peak linkage was detected at marker D19S930, revealing a multipoint HLOD of 2.55 at $\sim 40 \mathrm{cM}$ (Table 2 and Figure 2). Nonparametric analyses detected a LOD* of 1.92 and a corresponding NPL of $2.77(\mathrm{P}=$ 0.003 ). As with chromosome 17, the multipoint analyses show a second more telomeric peak, corresponding to marker D19S113. The recessive HLOD at this site was 2.20, with model-independent LOD* and NPL values of 1.39 and $2.10(\mathrm{P}=0.018)$, respectively.

To address the possibility of gene-gene interaction, we applied the OSA approach with family-specific LOD scores as the ranking trait. Families, almost all of which are affected sib-pairs, were ranked in both ascending and descending order using family-specific LOD scores. The three most significant correlations are presented in Figure 3. Using chromosome 19 LOD scores as the covariate, the results on chromosome $17 \mathrm{q}$, while non-significant $(\mathrm{P}=$ 0.1 ), showed an increase in linkage at the more distal peak on $17 \mathrm{q} 21.1$ from a LOD* of 1.7 to 3.6 and identified an optimal subset of 52 families. Applying the same covariate, a significant increase was seen on chromosome 6q, with a smaller, completely overlapping, 30-family optimal subset. This subset resulted in an increase in LOD* values from 1.0 to 3.6 at $164 \mathrm{cM}(\mathrm{P}=0.004)$. Another significant finding involves the $7 \mathrm{q}$ region, possibly representing the most replicated site of linkage in autism (reviewed in $[9,29]$ ). Given a substantial focus on this region over several years, we lessened our criteria to examine any other chromosome demonstrating a LOD score $>1$. Application of OSA using chromosome $7 \mathrm{q}$ linkage data, again ranking families based on LOD scores in a descending manner, lead to a significant increase in linkage on $5 p$ at $\sim 41 \mathrm{cM}$ from a LOD* of 1.1 to 3.3 in a 41 family subset. Thus, in these three cases, notwithstanding the nonsignificance of the $19 \mathrm{p} 13 / 17 \mathrm{q} 21$ result, there is a positive correlation of linkage in varying but overlapping subsets of the data between these respective pair-wise locus combinations.

To further explore the basis of the observed results, we tested the hypothesis that underlying phenotypic correlates might explain genetic correlations. We compared the mean values for the seven factor traits in the optimal subsets compared to the means of the remaining families using a t-test, both under assumption of equal and unequal variances. This comparison for all seven available factors revealed a nominally significant differences in the chromosome 19 optimal subsets identified from OSA analysis of chromosomes 17 (52 families) and 6 (30 families) for the "developmental milestones" cluster. The families in the optimal OSA subset have lower scores and therefore are more rapidly achieving developmental milestones. A similar procedure for the chromosome 7-based subset revealed no obvious differences in any of the factors (data not shown).

To directly test the hypothesis that chromosome 19 linkage was related to reduced affection for the "developmental milestones" factor, we performed an OSA analysis in which families were ranked in ascending order based on mean values for the milestones factor score. Figure 2 shows the results from this analysis, which generated increased evidence for linkage to 19 p 13 with peak LOD* scores increasing from 1.9 to 3.4. Permutation testing revealed this increase to be empirically significant $(\mathrm{P}=$ 0.04 ), thus further supporting $19 \mathrm{p} 13$ as harboring a genetic risk factor for autism.

\section{Discussion}

We have presented evidence in support of autism susceptibility loci on chromosomes $17 \mathrm{q}$ and $19 \mathrm{p}$. Our results 


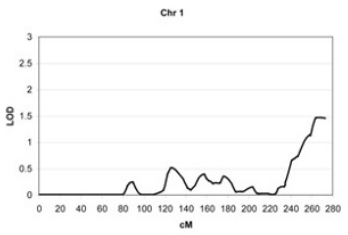

$\mathrm{Chr} 4$
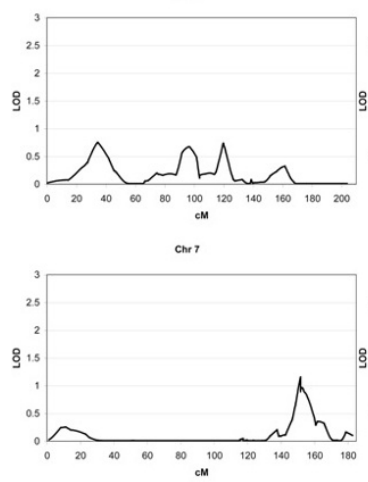

$\mathrm{Chr} 10$

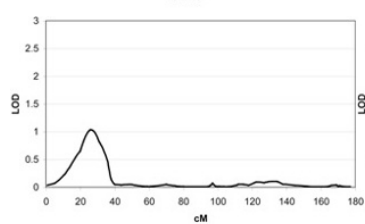

$\mathrm{Cns} 13$
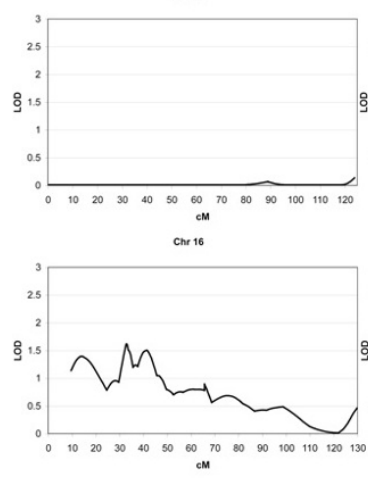

Chr 19

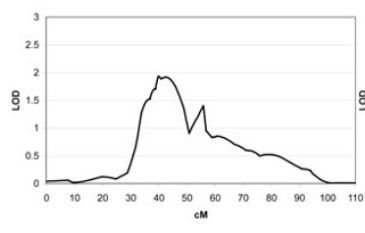

Chr 22

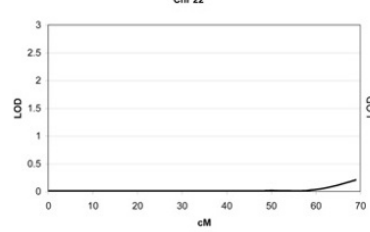

$\mathrm{con} 2$

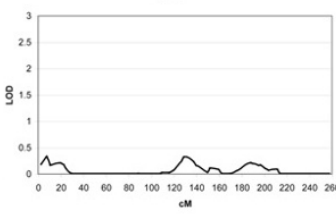

chrs
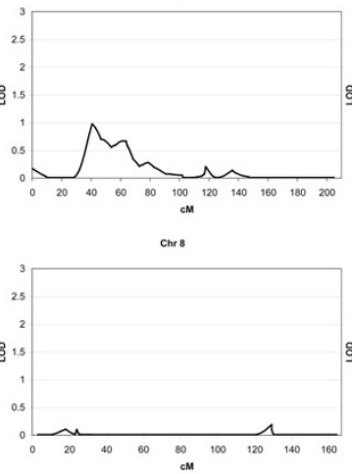

chrt 11

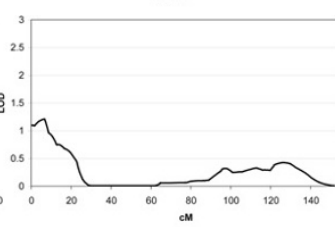

$\mathrm{Chr} 14$

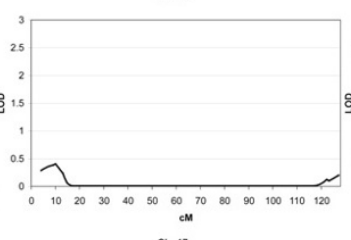

chr 17

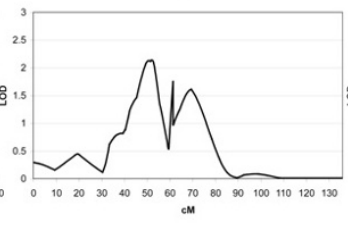

Chr 20
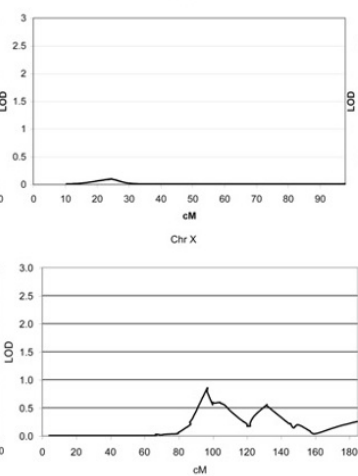

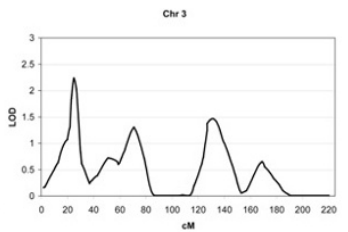

chres

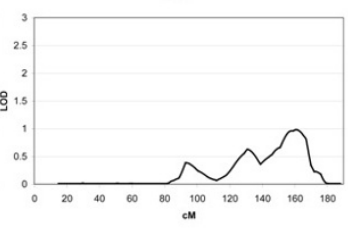

chrs

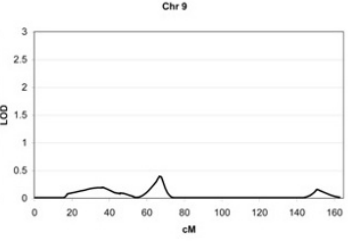

$\mathrm{Chr} 12$

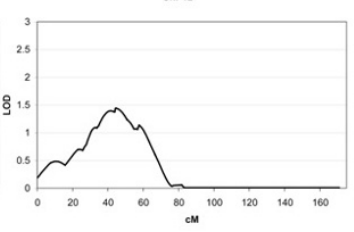

Chr is

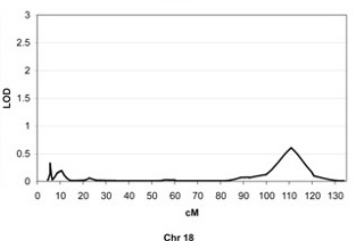

Che 18

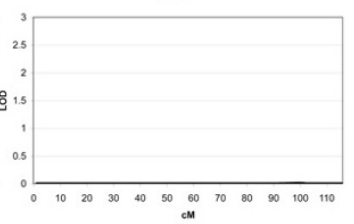

Chr 21

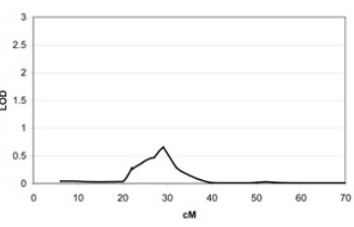

Figure I

Genome-wide nonparametric linkage analysis in 158 multiplex families for autism loci. Individual plots show allelesharing LOD* scores calculated for autosomes using Allegro and MLOD scores for the $\mathrm{X}$ chromosome calculated using ASPEX. 

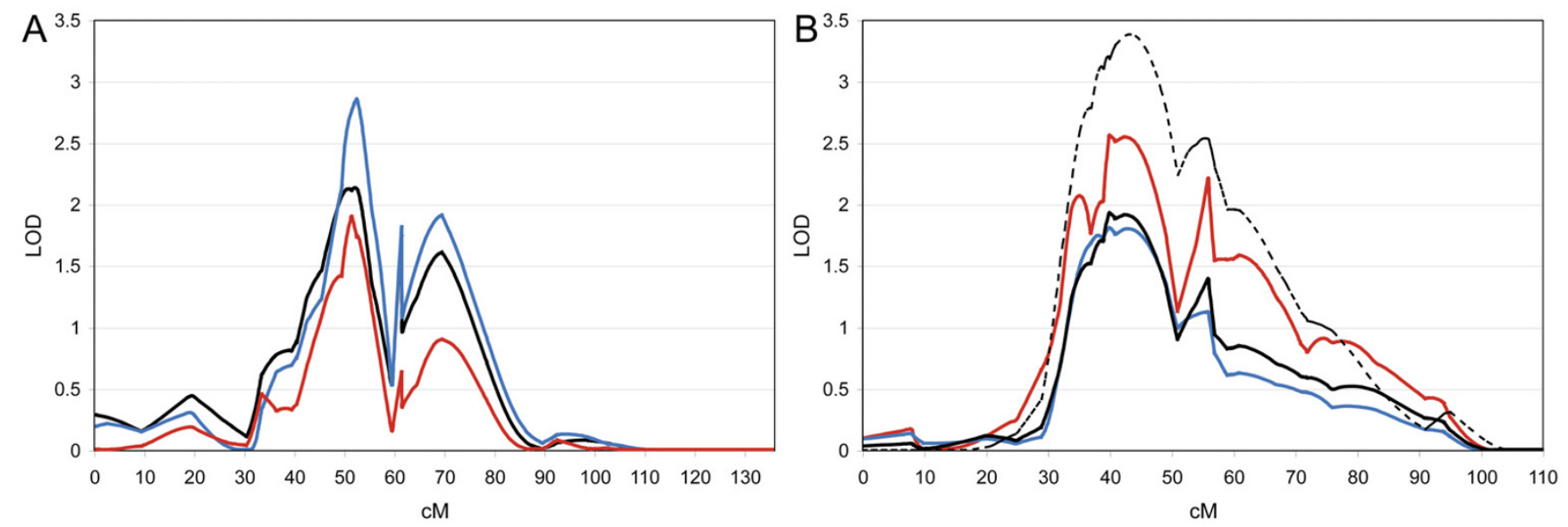

Figure 2

Multipoint linkage analysis under all models for chromosomes 17 (A) and 19 (B). Multipoint parametric HLOD plots for both dominant (blue) and recessive (red) models, and nonparametric allele-sharing LOD* values (black) are displayed across the respective chromosomes. OSA analysis using ascending "developmental milestones" factor scores to order families is shown for chromosome 19, for which a 92-family optimal subset was identified and used to calculate allele-sharing LOD* scores (dashed black line).

suggest that the $19 \mathrm{p}$ locus is related to a phenotypic profile involving a more rapid achievement of particular "developmental milestones". Features indexed in this ADI-based factor are: (1) ability to walk unaided; (2) ability to sit unaided on a flat surface; (3) age of first single words; (4) age of first phrase; (5-6) acquisition of bladder control: daytime and night; and (7) acquisition of bowel control. Analyses leading to this conclusion also showed positive genetic correlations between optimal OSAdefined subsets contributing to linkage at 19 p13 and increases in linkage at loci on 17q21 and 6q23. A similar positive genetic correlation was shown for chromosomes $7 \mathrm{q}$ and $5 \mathrm{p}$, however this observation lacks evidence of an underlying phenotypic relationship based on available ADI variable clusters. While the increase in linkage at 17 q21 was not empirically significant, the differences in "milestone" score means between the optimal chromosome 19 subsets seen for both chromosomes 17 (52 families) and $6 \mathrm{q}$ (30 families) were significant. These exploratory data led to the significant finding of increased linkage in the single direct test of our hypothesis concerning the phenotypic correlation related to chromosome 19 linkage.

Despite the significance of the final results on 19, we remain cautious in the interpretation of the overall results. As with a number of other genomic screens in autism, no single main effect locus achieved genome-wide significance. Support for a number of these loci, particularly at $17 \mathrm{q} 11.2$ and $19 \mathrm{p} 13$ comes from similar suggestive linkage in other genomic screens for autism. Although not all screens detect these loci (not an uncommon finding in linkage studies for complex genetic disorders), the evidence is strong regarding an effect at $19 \mathrm{p}$, within $10 \mathrm{cM}$ of our peak: (1) Shao et al reported an MMLS $=1.21$ and an MLOD $=1.38$ [14]; (2) the Paris Autism Research International Sibpair Study (PARIS) an MMLS = 1.37 [12]; the International Molecular Genetic Study of Autism Consortium (IMGSAC) reported an MLS of 1.16 [15]; the Mt. Sinai group reported an NPL of 1.56 which increased to 2.31 when only families with obsessive-compulsive behaviors were considered for this region [22].

Similarly, several groups have reported evidence for linkage at $17 \mathrm{q} 11$. The recently published AGRE follow-up genomic screen identified an MLS of 2.83 near SLC6A4 [21]. A genome scan for attention deficit/hyperactivity disorder (ADHD) identified an MLS of 2.98 near this locus [57]. An IMGSAC follow-up screen for autism [27] reported a maximum multipoint LOD score of 2.34 at HTTINT2 in the SLC6A4 gene on chromosome 17q11.2. Our own more preliminary analysis of linkage in this region with a highly overlapping dataset to that in the current study, revealed very similar results [58]. Given our inclusion of some AGRE families, it is not completely unexpected that $17 \mathrm{q} 11.2$ linkage is similar to that seen the larger AGRE $2^{\text {nd }}$-stage screen [21], however AGRE families only represented about half of the overall dataset. Families recruited from the Tufts/NEMC site are clearly 

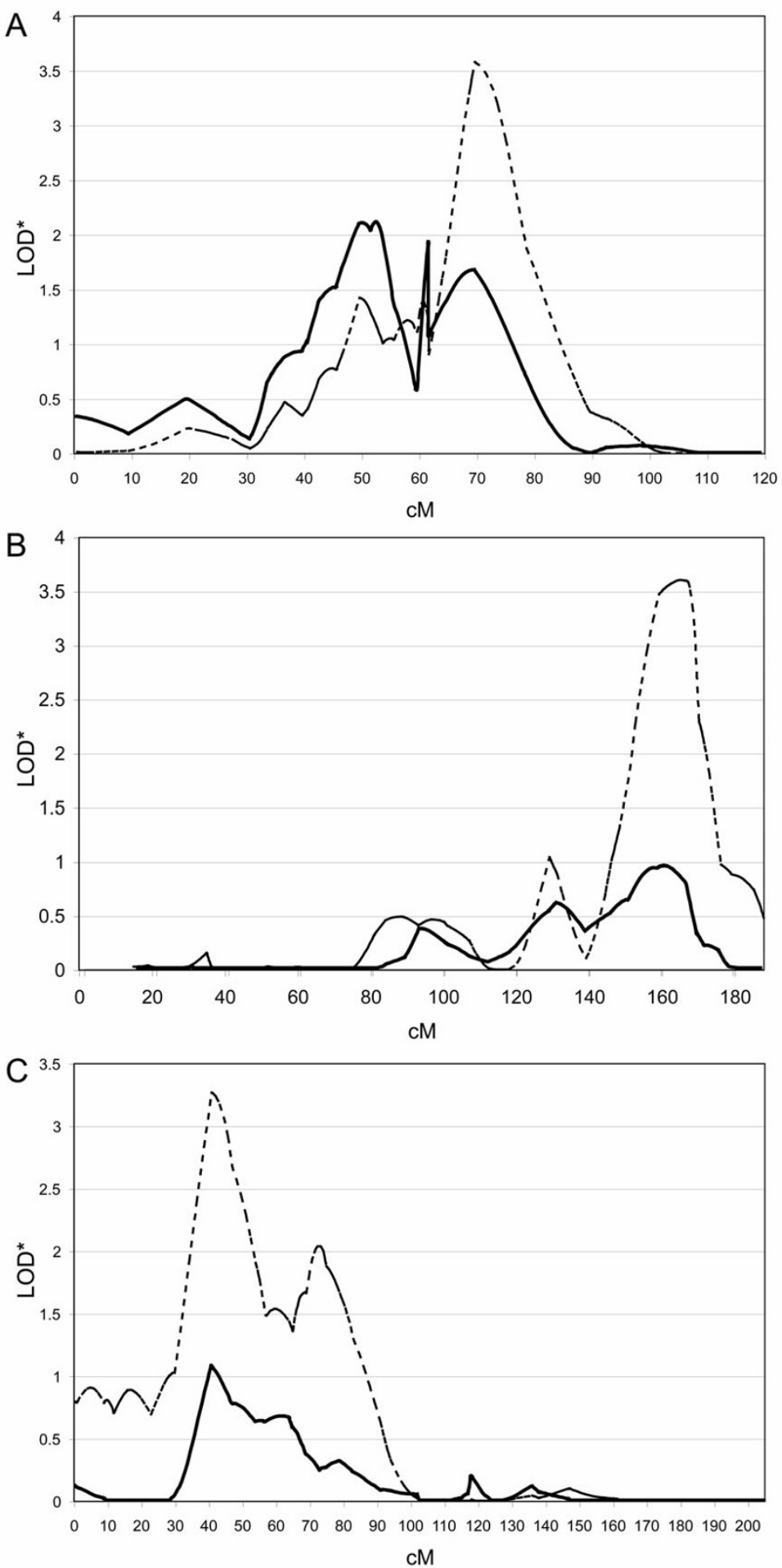

Figure 3

OSA using family-specific LOD scores as the ranking covariate. Families were ordered based on descending LOD scores at peak linkage for 19p/3 and allele-sharing LOD scores calculated in the optimal subset for (A) chromosome I7 or (B) chromosome 6. Families were also ranked based on descending LOD scores at peak linkage on chromosome 7q (C), and LOD scores calculated for chromosome 5. Solid lines reflect multipoint LOD scores corresponding to the entire dataset for the chromosome being analyzed, while dashed lines represent analysis of the optimal subset (above the dataset division in all cases) identified from OSA; these were 52 families for chromosome 17, 30 for chromosome 6 and 4I families for chromosome 7. 
contributing to this linkage based on the LOD score-based optimal family subset compositions.

The $17 \mathrm{q} 21$ locus is worth further consideration. Our data support the premise that the adjacent linkage peaks represent distinct loci and are not an artifact of primary linkage at $17 \mathrm{q} 11.2$. The evidence for linkage at $17 \mathrm{q} 21$, while weaker than that at $17 \mathrm{q} 11.2$ only $16 \mathrm{cM}$ centromeric, specifically showed an, albeit nonsignificant, interlocus correlation with $19 \mathrm{p} 13$ linkage. Linkage at $17 \mathrm{q} 11.2$ in this subset of families actually decreases slightly. Of particular interest is the fact that the distal region harbors the integrin $\beta 3$ (ITGB3) locus, which was identified recently from a genome-wide quantitative trait locus (QTL) association screen for platelet serotonin levels [59]. We see nominal evidence of linkage to autism at this site, and $\sim 20-25 \%$ of individuals with autism have elevated levels of circulating serotonin.

The other "suggestive" (LOD $\geq 1.5$ ) loci reported here have also been detected in other genome-wide scans for autism loci. A broad region of $7 \mathrm{q}$ has been detected in most screens $[17,20,23,25,27,28]$. The $16 \mathrm{p}$ region has been identified by IMGSAC, and others $[15,18,22,27]$. Chromosomal abnormalities have also been reported for several of these regions in cases of autism (reviewed in [11]). Linkage at $3 p$ was reported by at least two groups $[14,17]$. Linkage has also been reported at our $6 \mathrm{q}$ locus by at least one other group [12]. Thus, while not significant, the replication of these linkage observations provides support for the likelihood that many of these loci represent true sites of main effect in autism.

The application of OSA to detect putative interlocus correlations between the 19p13 and 17q21, 19p13 and 6q23, and between $7 \mathrm{q} 35$ and $5 \mathrm{p}$ are limited to some degree in significance by their highly exploratory and hypothesisgenerating nature. Given the number of comparisons between loci, and the number of comparisons between optimal subset pairs (on 19p or $7 \mathrm{q}$ ) for the traits means, the potential for type I error is increased. Therefore our interpretation must be cast alongside appropriate caveats. Nevertheless, the multiple exploratory comparisons generated a hypothesis: that linkage to $19 p 13$ was related to a more rapid achievement for specific milestones. We tested this hypothesis with a single analysis revealing an empirically significant increase in linkage at 19p13. Our results of autism linkage and its increase using an ascending milestone score covariate in OSA, taken in the context of replicated observations of suggestive linkage by other groups, strengthens support for the presence of an autism gene at this site. In the end, ultimate interpretation will rely upon replication of these phenomena with independent samples to confirm these observations.
Finally, our results highlight the utility of using trait-based subsets of autism to identify putative susceptibility loci for this complex disorder. We and others have hypothesized a likely increased specificity of individual risk genes and corresponding alleles for traits or subphenotypes comprising the broader autism spectrum. Therefore methods such as OSA with power to identify more homogeneous samples and QTL (quantitative trait locus) linkage and association analyses should provide greater sensitivity in the discovery of disease genes in the context of locus and clinical heterogeneity. Additionally, OSA or other forms of conditional linkage analyses, have the ability to uncover potential interactions between loci, an important concept since the inherent interdependence of proteins in common pathways or networks acting during development and normal neuronal function could be easily imagined to act genetically in concert with one another.

\section{Conclusions}

We report evidence to support linkage of autism to $17 \mathrm{p} 11.2$ and 19p13. Exploratory analyses to test for correlations between suggestively-linked loci, using the OSA method revealed positive correlations of linkage (i.e. in overlapping families) between $7 \mathrm{q}$ and $5 \mathrm{p}, 19 \mathrm{p}$ and $6 \mathrm{q}$, and possibly $19 \mathrm{p}$ and $17 \mathrm{q} 22$, distal to peak linkage at 17q11.2. Comparing mean scores for ADI-derived factor traits from families above and below the OSA-defined split maximizing linkage, suggested a positive correlation between 19p13 linkage and a more rapid achievement of "developmental milestones" as measured by items in this cluster of ADI variables. We tested this hypothesis by applying OSA with descending "developmental milestone" scores as the ranking covariate, and detected an empirically-significant increase in linkage to 19p13. These findings further support evidence for an autism susceptibility locus in 19p13 and underscore the utility in applying trait subsets in complex disorders to identify genetic risk factors.

\section{Competing interests}

The authors declare that they have no competing interests.

\section{Authors' contributions}

JLM and LMO were responsible for conducting the genome-wide linkage analyses; JLM conducted all OSA analyses, was largely responsible for coordinating and executing the bulk of the reported studies, was key to drafting and editing the manuscript text, and in preparing the figures. CL and JLH provided input into the design and interpretation of statistical results, and provided guidance for conducting the genome-wide simulations required to determine the significance threshold. JLH established the Core-based infrastructure in the Center for Human Genetics Research that facilitated this work and 
provided very helpful input into the development of the manuscript. SEF developed, with her group, the ADIbased clusters so crucial to examining phenotypic subsets in this paper, which she helped to edit. SEF was responsible for overseeing recruitment and the phenotypic assessment of families from her research group, then at Tufts/NEMC. GC is the clinical coordinator at the Vanderbilt site and oversees ascertainment, recruitment and detailed phenotypic assessment of affected individuals. $\mathrm{KG}$ is the Vanderbilt data coordinator and is responsible for management and oversight of family information, pedigree data, and status of DNA, blood or cell line samples for family members. She is directly responsible for preparation of Table 1 of this paper. JSS and JLH are Principal Investigator (PI) and co-PI, respectively, of the current study, and together conceived of and implemented the experimental strategy in close consultation with all other co-authors. JSS initially drafted the manuscript and with JLM incorporated changes suggested by co-authors. JSS was responsible for preparation of all final versions of figures from earlier versions provided by co-authors.

\section{Acknowledgements}

We acknowledge the important contributions to this work from staff in the Vanderbilt Center for Human Genetics Research, including the DNA Resources, Data Analysis, Family Ascertainment, and Bioinformatics Cores. We also thank the invaluable contributions of Brian Winkloski, Beth RosenSheidley C.G.C., and Dr. Michael Dowd for their hard work at the Tufts/ NEMC site and contributions to the early phases of this work. Funding for this work was supported in part by NIH grants MH6I009 to JSS, MH55I35 to SEF (PI) and JSS (Co-PI); a Vanderbilt Kennedy Center Hobbs Discovery Research Award to JSS and a National Alliance for Autism Research (NAAR) predoctoral fellowship for JLM, and NIH grant NS26630 to Margaret Pericak-Vance (Duke Center for Human Genetics) and JLH. Some of this work was also supported through the Vanderbilt General Clinical Research Center (RR 00095).

We especially wish to acknowledge the families who participated in this research, including the AGRE families and resources provided by the AGRE consortium, without whose contribution, none of this work would be possible.

\section{References}

I. Yeargin-Allsopp M, Rice C, Karapurkar T, Doernberg N, Boyle C, Murphy C: Prevalence of autism in a US metropolitan area. JAMA 2003, 289:49-55.

2. Volkmar FR, Szatmari P, Sparrow SS: Sex differences in pervasive developmental disorders. J Autism Dev Disord 1993, 23:579-59।.

3. McLennan JD, Lord C, Schopler E: Sex differences in higher functioning people with autism. J Autism Dev Disord 1993, 23:217-227.

4. Folstein S, Rutter M: Infantile autism: a genetic study of 21 twin pairs. J Child Psychol Psychiatry 1977, I 8:297-32I.

5. Rutter M, Macdonald H, Le Couteur A, Harrington R, Bolton P, Bailey A: Genetic factors in child psychiatric disorders - II. Empirical findings. J Child Psychol Psychiatry 1990, 3 I:39-83.

6. Jones MB, Szatmari P: Stoppage rules and genetic studies of autism. J Autism Dev Disord 1988, 18:31-40.

7. Pickles A, Bolton P, Macdonald H, Bailey A, Le Couteur A, Sim CH, Rutter M: Latent-class analysis of recurrence risks for complex phenotypes with selection and measurement error: a twin and family history study of autism. Am J Hum Genet 1995, 57:717-726.
8. Szatmari $P$, Jones MB: Effects of misclassification on estimates of relative risk in family history studies. Genet Epidemiol 1999 , 16:368-38I.

9. Folstein SE, Rosen-Sheidley B: Genetics of autism: complex aetiology for a heterogeneous disorder. Nat Rev Genet 200I, 2:943-955.

10. Muhle R, Trentacoste SV, Rapin I: The genetics of autism. Pediatrics 2004, I I 3:e472-486.

II. Veenstra-VanderWeele J, Christian SL, Cook JEH: Autism as a Paradigmatic Complex Genetic Disorder. Annu Rev Genomics Hum Genet 2004, 5:397-405.

12. Philippe A, Martinez M, Guilloud-Bataille M, Gillberg C, Rastam M, Sponheim E, Coleman M, Zappella M, Aschauer H, van Malldergerme L, Penet C, Feingold J, Brice A, Leboyer M: Genome-wide scan for autism susceptibility genes. Hum Mol Genet 1999, 8:805-8I2.

13. Collaborative Linkage Study of Autism: An autosomal genomic screen for autism. Am J Med Genet 1999, 88B:609-6I5.

14. Shao Y, Wolpert CM, Raiford KL, Menold MM, Donnelly SL, Ravan SA, Bass MP, McClain C, von Wendt L, Vance JM, Abramson RH, Wright $\mathrm{HH}$, Ashley-Koch A, Gilbert JR, DeLong RG, Cuccaro ML, Pericak-Vance MA, McCoy PA: Genomic screen and follow-up analysis for autistic disorder. Am J Med Genet 2002, I I 4B:99- 105.

15. International Molecular Genetic Study of Autism Consortium: A full genome screen for autism with evidence for linkage to a region on chromosome 7q. Hum Mol Genet 1998, 7:57I-578.

16. Risch N, Spiker D, Lotspeich L, Nouri N, Hinds D, Hallmayer J, Kalaydjieva L, McCague P, Dimiceli S, Pitts T, Nguyen L, Yang J, Harper C, Thorpe D, Vermeer S, Young H, Hebert J, Lin A, Ferguson J, Chiotti C, Wiese-Slater S, Rogers T, Salmon B, Nicholas P, Petersen PB, Pingree C, McMahon W, Wong DL, Cavalli-Sforza LL, Kraemer HC, Myers RM: A genomic screen of autism: Evidence for a multilocus etiology. Am J Hum Genet 1999, 65:493-507.

17. Auranen M, Nieminen T, Majuri S, Vanhala R, Peltonen L, Jarvela I: Analysis of autism susceptibility gene loci on chromosomes Ip, 4p, 6q, 7q, 13q, 15q, 16p, 17q, 19q and 22q in Finnish multiplex families. Mol Psychiatry 2000, 5:320-322.

18. Liu J, Nyholt DR, Magnussen P, Parano E, Pavone P, Geschwind D Lord C, Iversen P, Hoh J, Ott J, Gilliam TC, The Autism Genetic Resource Exchange: A genomewide screen for autism susceptibility loci. Am J Hum Genet 200I, 69:327-340.

19. Buxbaum JD, Silverman JM, Smith CJ, Kilifarski M, Reichert J, Hollander E, Lawlor BA, Fitzgerald M, Greenberg DA, Davis KL: Evidence for a susceptibility gene for autism on chromosome 2 and for genetic heterogeneity. Am J Hum Genet 200I, 68:1514-1520.

20. International Molecular Genetic Study of Autism C: Further characterization of the autism susceptibility locus AUTSI on chromosome 7q. Hum Mol Genet 200I, I 0:973-982

21. Yonan AL, Alarcon M, Cheng R, Magnusson PK, Spence SJ, Palmer AA, Grunn A, Hank Juo SH, Terwilliger JD, Liu J, Cantor RM, Geschwind DH, Gilliam TC: A genomewide screen of $\mathbf{3 4 5}$ families for autism-susceptibility Loci. Am J Hum Genet 2003, 73:886-897.

22. Buxbaum JD, Silverman J, Keddache M, Smith C], Hollander E, Ramoz $\mathrm{N}$, Reichert JG: Linkage analysis for autism in a subset families with obsessive-compulsive behaviors: evidence for an autism susceptibility gene on chromosome I and further support for susceptibility genes on chromosome 6 and 19. Mol Psychiatry 2004, 9: 144-150.

23. Ashley-Koch A, Wolpert CM, Menold MM, Zaeem L, Basu S, Donnelly SL, Ravan SA, Powell CM, Qumsiyeh MB, Aylsworth AS, Vance JM, Gilbert JR, Wright HH, Abramson RK, DeLong GR, Cuccaro ML, Pericak-Vance MA: Genetic studies of autistic disorder and chromosome 7. Genomics 1999, 61:227-236.

24. Folstein SE, Mankoski RE: Chromosome 7q: where autism meets language disorder? Am J Hum Genet 2000, 67:278-28I.

25. Collaborative Linkage Study of Autism: Incorporating language phenotypes strengthens evidence of linkage to autism. Am J Med Genet 200I, 105:539-547.

26. Shao Y, Raiford KL, Wolpert CM, Cope HA, Ravan SA, Ashley-Koch AA, Abramson RK, Wright HH, DeLong RG, Gilbert JR, Cuccaro ML, Pericak-Vance MA: Phenotypic homogeneity provides increased support for linkage on chromosome 2 in autistic disorder. Am J Hum Genet 2002, 70: 1058-106I.

27. International Molecular Genetic Study of Autism Consortium: A genomewide screen for autism: strong evidence for linkage 
to chromosomes 2q, 7q, and 16p. Am J Hum Genet 200I, 69:570-58।.

28. Alarcon M, Cantor RM, Liu J, Gilliam TC, Geschwind DH, Autism Genetics Resource Exchange: Evidence for a language quantitative trait locus on chromosome $7 q$ in multiplex autism families. Am J Hum Genet 2002, 70:60-7I.

29. Veenstra-VanderWeele J, Cook EH: Molecular genetics of autism spectrum disorder. Mol Psychiatry 2004, 9:819-823.

30. Jiang Y-h, Sahoo T, Michaelis RC, Bercovich D, Bressler J, Kashork CD, Liu Q, Shaffer LG, Schroer RJ, Stockton DW, Spielman RS, Stevenson $R E$, Beaudet $A L$ : A mixed epigenetic/genetic model for oligogenic inheritance of autism with a limited role for UBE3A. Am J Med Genet 2004, I 3 I A: I I 0.

31. Lord C, Rutter M, Le Couteur A: Autism Diagnostic InterviewRevised: a revised version of a diagnostic interview for caregivers of individuals with possible pervasive developmental disorders. J Autism Dev Disord 1994, 24:659-685.

32. Lord C, Rutter M, Goode S, Heemsbergen J, Jordan H, Mawhood L Schopler E: Autism diagnostic observation schedule: a standardized observation of communicative and social behavior. Autism Dev Disord 1989, 19:185-2/2.

33. Lord C, Pickles A, McLennan J, Rutter M, Bregman J, Folstein S, Fombonne E, Leboyer M, Minshew N: Diagnosing autism: analyses of data from the Autism Diagnostic Interview. J Autism Dev Disord 1997, 27:50I-5I7.

34. DiLavore PC, Lord C, Rutter M: The pre-linguistic autism diagnostic observation schedule. J Autism Dev Disord 1995, 25:355-379.

35. Sparrow SS, Cicchetti DV: Diagnostic uses of the Vineland Adaptive Behavior Scales. J Pediatr Psychol 1985, 10:2 I 5-225.

36. Volkmar FR, Sparrow SS, Goudreau D, Cicchetti DV, Paul R, Cohen $D$ J: Social deficits in autism: an operational approach using the Vineland Adaptive Behavior Scales. J Am Acad Child Adolesc Psychiatry 1987, 26:156-16I.

37. Kong A, Gudbjartsson DF, Sainz J, Jonsdottir GM, Gudjonsson SA Richardsson B, Sigurdardottir S, Barnard J, Hallbeck B, Masson G, Shlien A, Palsson ST, Frigge ML, Thorgeirsson TE, Gulcher JR, Stefansson $\mathrm{K}$ : A high-resolution recombination map of the human genome. Nat Genet 2002, 3 I:24I-247.

38. Autism Genetics Resource Exchange [http://agre.org]

39. Geschwind DH, Sowinski J, Lord C, Iversen P, Shestack J, Jones P, Ducat L, Spence S): The Autism Genetic Resource Exchange: a resource for the study of autism and related neuropsychiatric conditions. Am J Hum Genet 200I, 69:463-466.

40. O'Connell JR, Weeks DE: PedCheck: a program for identification of genotype incompatibilities in linkage analysis. $\mathrm{Am} \mathrm{J}$ Hum Genet 1998, 63:259-266.

4I. RELPAIR [http://www.sph.umich.edu/statgen/boehnke/ relDair.html]

42. Weeks DE, Sobel E, O'Connell JR, Lange K: Computer programs for multilocus haplotyping of general pedigrees. Am J Hum Genet 1995, 56:1506-1507.

43. Haynes CS, Speer MC, Peedin M, Roses AD, Haines JL, Vance JM, Pericak-Vance MA: A comprehensive data management system to facilitate efficient and rapid disease gene mapping. Am J Hum Genet 1995, 57:Al93.

44. Gudbjartsson DF, Jonasson K, Frigge ML, Kong A: Allegro, a new computer program for multipoint linkage analysis. Nat Genet 2000, 25:12-13.

45. McPeek MS: Optimal allele-sharing statistics for genetic mapping using affected relatives. Genet Epidemiol 1999, 16:225-249.

46. [http://aspex.sourceforge.net/]

47. Cottingham RW Jr, Idury RM, Schaffer AA: Faster sequential genetic linkage computations. Am J Hum Genet I993, 53:252-263.

48. Sawcer S, Jones HB, Judge D, Visser F, Compston A, Goodfellow PN, Clayton D: Empirical genomewide significance levels established by whole genome simulations. Genet Epidemiol 1997, 1 4:223-229.

49. Kruglyak L, Daly MJ: Linkage thresholds for two-stage genome scans. Am J Hum Genet 1998, 62:994-997.

50. Abecasis GR, Cherny SS, Cookson WO, Cardon LR: Merlin - rapid analysis of dense genetic maps using sparse gene flow trees. Nat Genet 2002, 30:97-I0I.

51. Mauser ER, Watanabe RM, Duren WL, Bass MP, Langefeld CD, Boehnke M: Ordered-Subset analysis in genetic linkage mapping of complex traits. Genet Epidemiol 2004, 27:53-63.
52. Shao Y, Cuccaro ML, Hauser ER, Raiford KL, Menold MM, Wolpert CM, Ravan SA, Elston L, Decena K, Donnelly SL, Abramson RK, Wright HH, DeLong GR, Gilbert JR, Pericak-Vance MA: Fine mapping of autistic disorder to chromosome $|5 \mathrm{q}| \mathrm{I}-\mathrm{q} \mid 3$ by use of phenotypic subtypes. Am J Hum Genet 2003, 72:539-548.

53. Scott WK, Hauser ER, Schmechel DE, Welsh-Bohmer KA, Small GW, Roses AD, Saunders AM, Gilbert JR, Vance JM, Haines JL, PericakVance MA: Ordered-Subsets linkage analysis detects novel Alzheimer disease loci on chromosomes 2q34 and I5q22. Am J Hum Genet 2003, 73: 104I-I05I.

54. Schmidt S, Scott WK, Postel EA, Agarwal A, Hauser ER, De La Paz MA, Gilbert JR, Weeks DE, Gorin MB, Haines JL, Pericak-Vance MA: Ordered Subset linkage analysis supports a susceptibility locus for age-related macular degeneration on chromosome |6p | 2. BMC Genet 2004, 5: I8.

55. Tadevosyan-Leyfer O, Dowd M, Mankoski R, Winklosky B, Putnam S, McGrath L, Tager-Flusberg H, Folstein SE: A Principal Components Analysis of the Autism Diagnostic Interview-Revised. J Am Acad Child Adolesc Psychiatry 2003, 42:864-872.

56. Cuccaro ML, Shao Y, Grubber J, Slifer M, Wolpert CM, Donnelly SL, Abramson RK, Ravan SA, Wright HH, DeLong GR, Pericak-Vance $M A:$ Factor analysis of restricted and repetitive behaviors in autism using the Autism Diagnostic Interview-R. Child Psychiatry Hum Dev 2003, 34:3-17.

57. Ogdie MN, Macphie IL, Minassian SL, Yang M, Fisher SE, Francks C, Cantor RM, McCracken JT, McGough J], Nelson SF, Monaco AP, Smalley SL: A genomewide scan for attention-deficit/hyperactivity disorder in an extended sample: suggestive linkage on I 7p I I. Am J Hum Genet 2003, 72: I 268- I 279.

58. McCauley JL, Olson LM, Dowd M, Amin T, Steele A, Blakely RD, Folstein SE, Haines JL, Sutcliffe JS: Linkage and association analysis at the serotonin transporter (SLC6A4) locus in a rigid-compulsive subset of autism. Am J Med Genet B Neuropsychiatr Genet 2004, 127:104-12.

59. Weiss LA, Veenstra-VanderWeele J, Newman DL, Kim SJ, Dytch H, McPeek MS, Cheng S, Ober C, Cook EH, Abney M: Genome-wide association study identifies ITGB3 as a OTL for whole blood serotonin. Eur J Hum Genet 2004, 12:949-954.

\section{Pre-publication history}

The pre-publication history for this paper can be accessed here:

\section{http://www.biomedcentral.com/1471-2350/6/1/prepub}

Publish with BioMed Central and every scientist can read your work free of charge

"BioMed Central will be the most significant development for disseminating the results of biomedical research in our lifetime. "

Sir Paul Nurse, Cancer Research UK

Your research papers will be:

- available free of charge to the entire biomedical community

- peer reviewed and published immediately upon acceptance

- cited in PubMed and archived on PubMed Central

- yours - you keep the copyright
BioMedcentral 